\title{
التغيرات البيئية واحتمالاتها المستقبلية في مصر
}

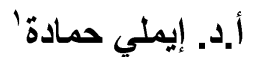

مقدمة:

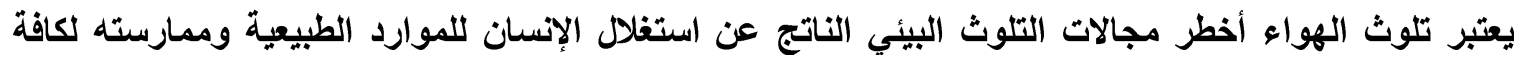

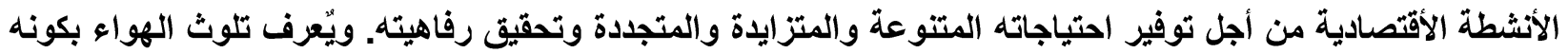

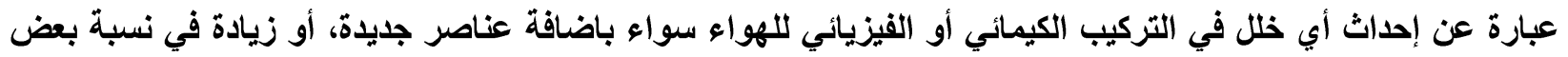

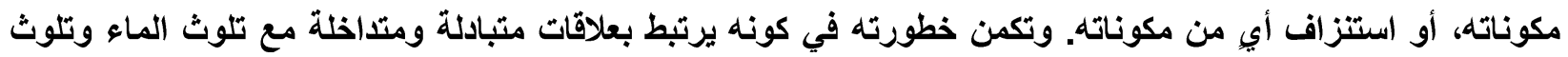

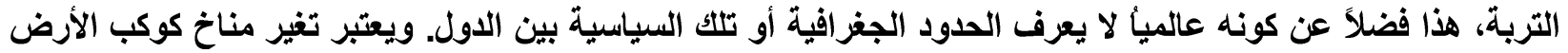
أحد أهم مظاهر تلوث الهواء التي تهلد البيئة وحياة الإنسان.

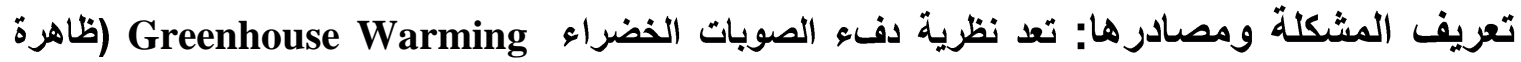

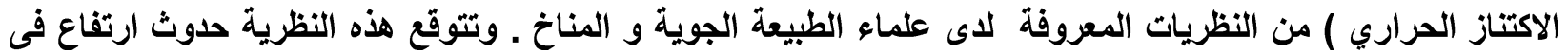

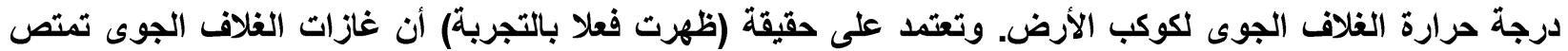

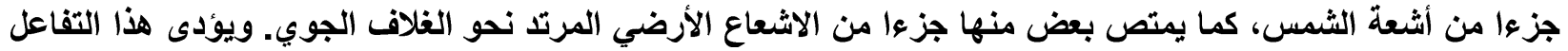

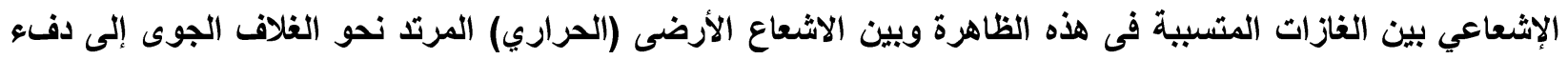

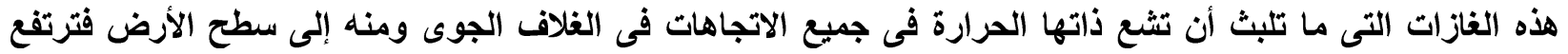

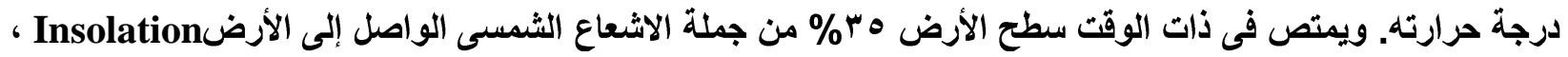

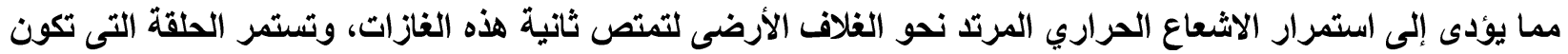
محصلتها ظاهرة الاكتناز الحراري.

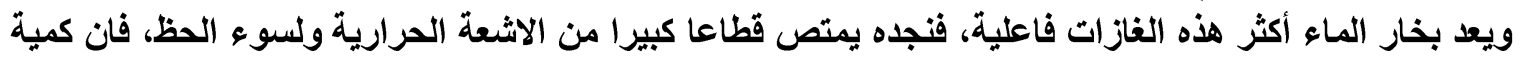

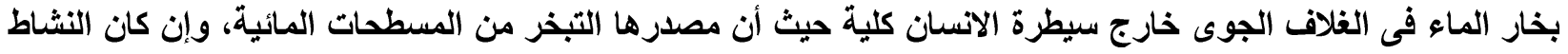

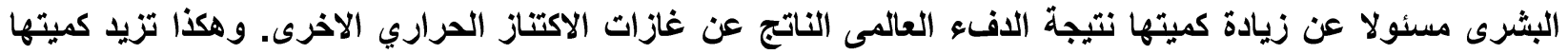

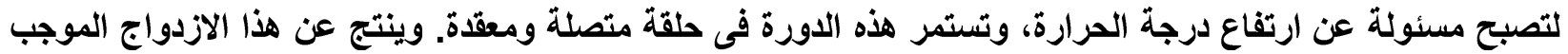

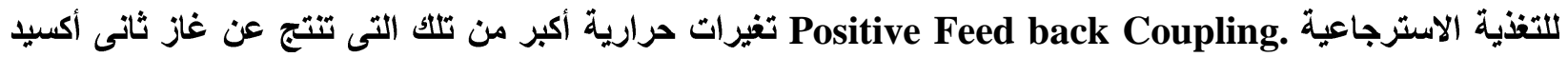

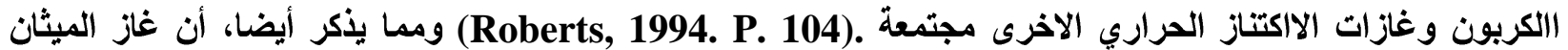

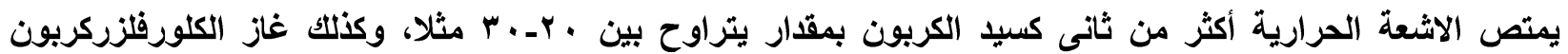

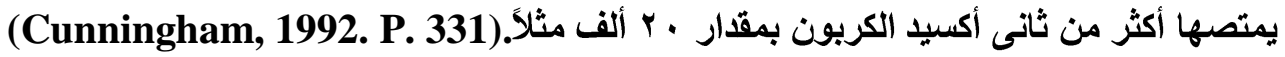

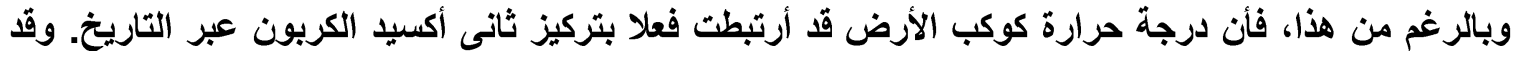

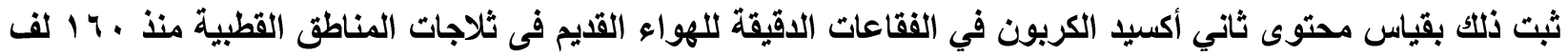

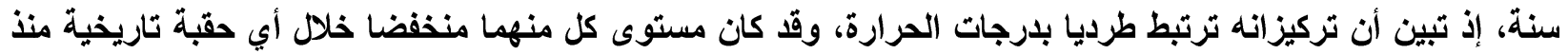

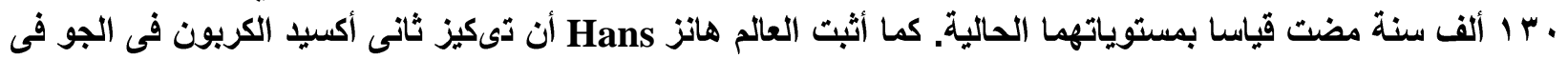
أثناء عصر الجلي الاخير بلغ نحو ثلثى مستواه في الفترة بين الجليدية التي سبقته

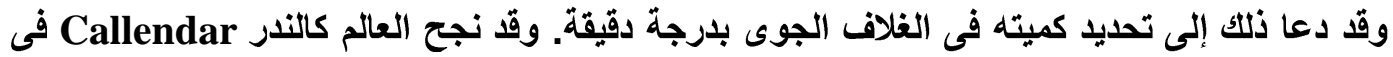

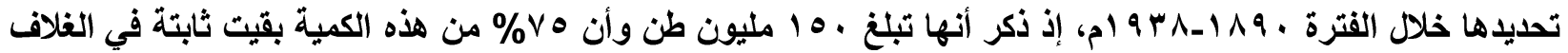

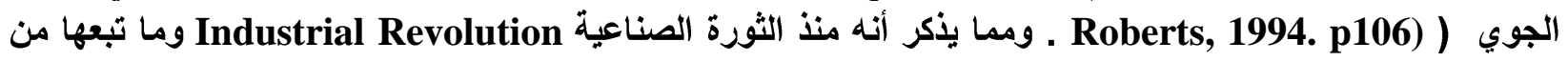


إستغلال كثيف للوقود الحفرى وتطور صناعة الاسمنت والتوسع فى قطع الاشجار لإستخدامها فى الصناعات الخشبية

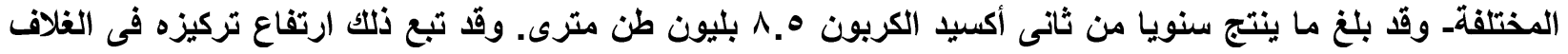

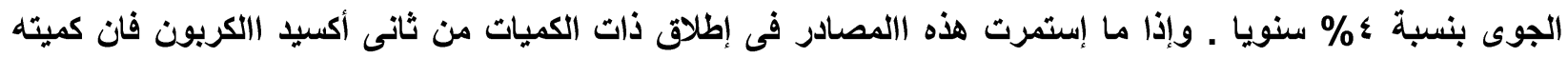

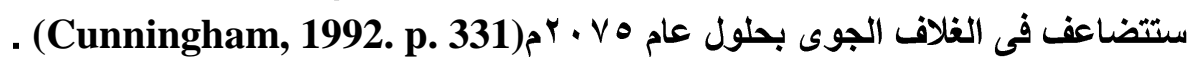

\section{مظاهر تغير مناخ الأرض والآثار العالمية المرتقبة:}

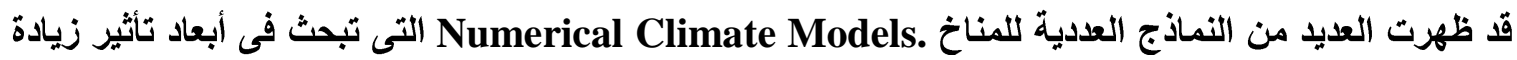

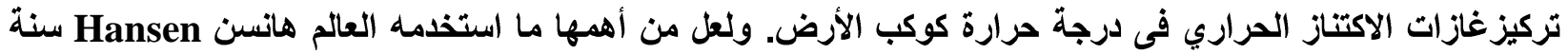

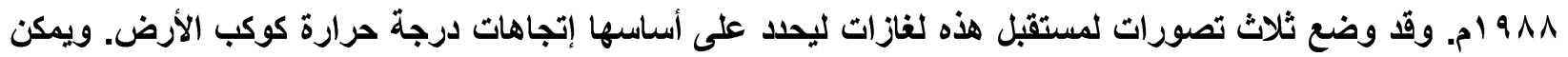
إيجاز أهم مظاهر تغير المناخ والآثار البيئية المرتقبة على لفئ المستوى العالمي والإقليمي في:

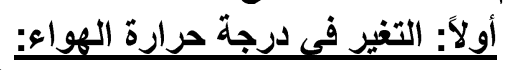

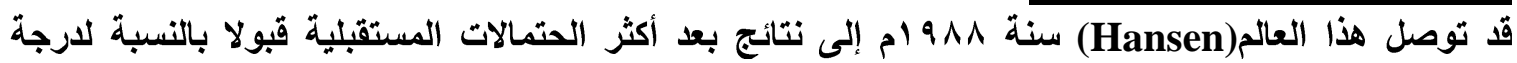

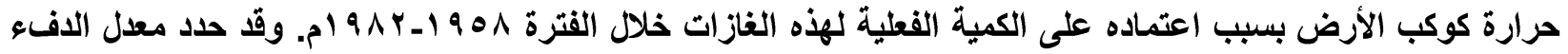

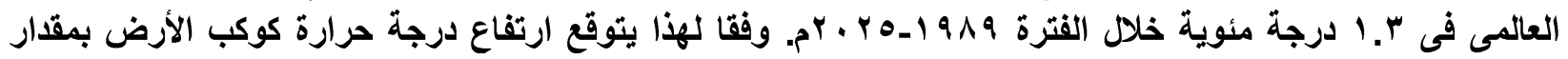

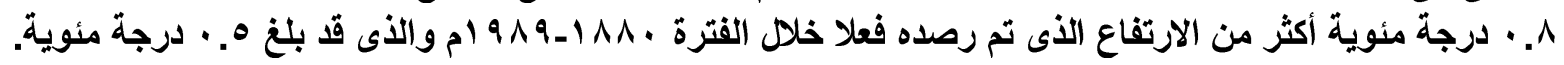

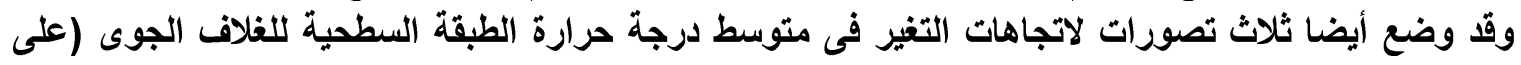

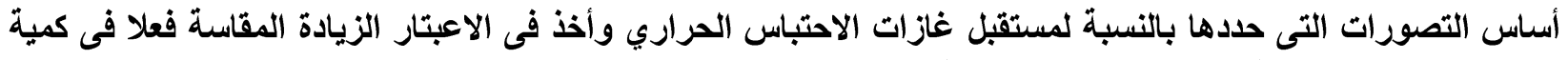

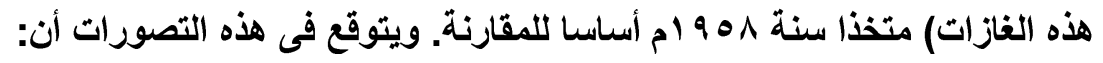

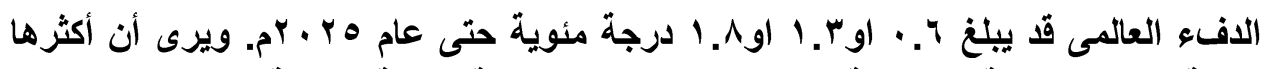

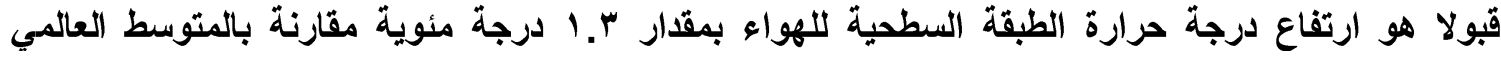

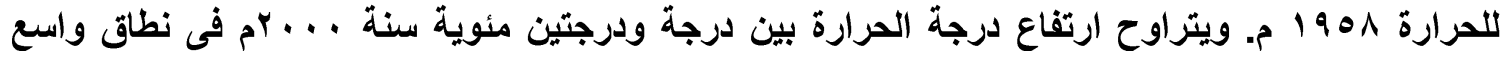

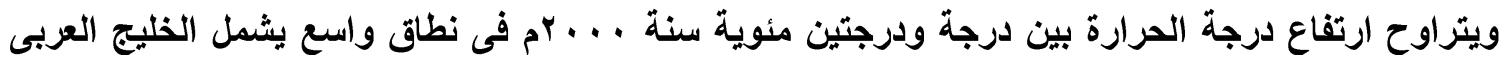

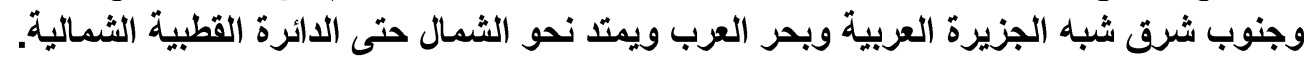

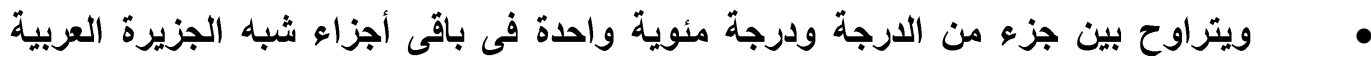

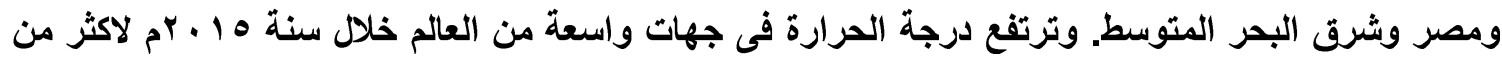

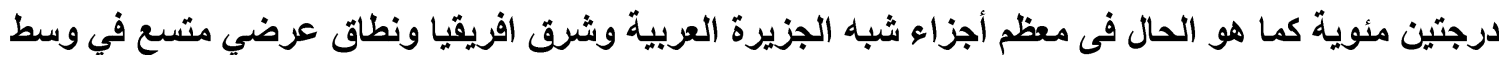

آسيا).

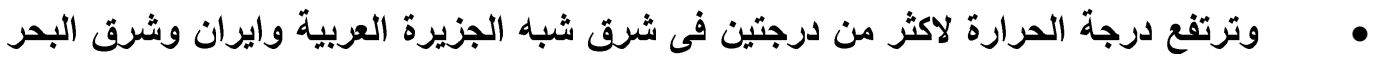

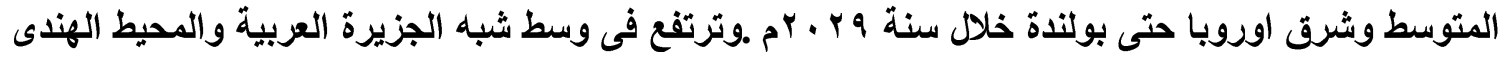

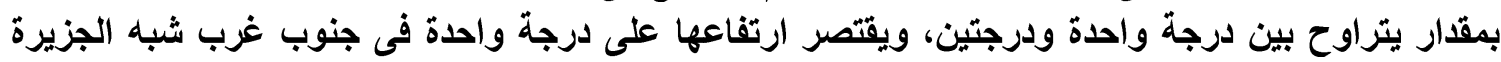

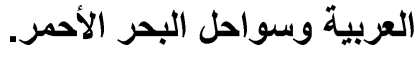

هذا وإن كان تضاعف كمية ثانى أكسيد الكريون (بوصفه نائبا عن مختلف غازات الاحتباس الحراري)

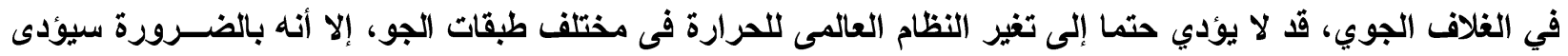

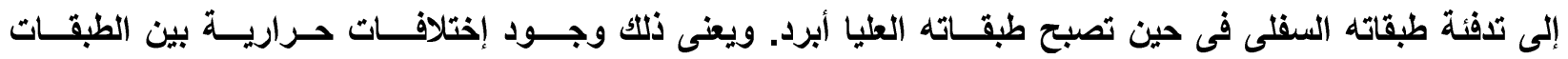

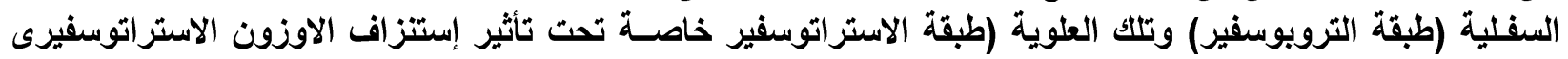

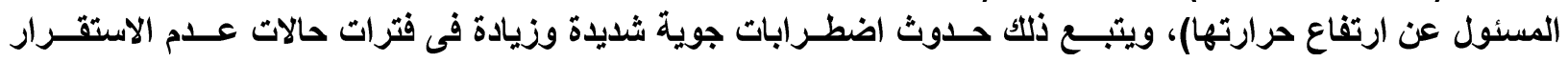

.(Bryant, 1980 p. 144).

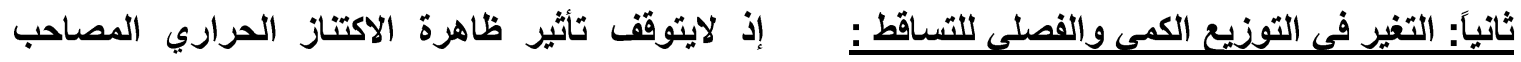

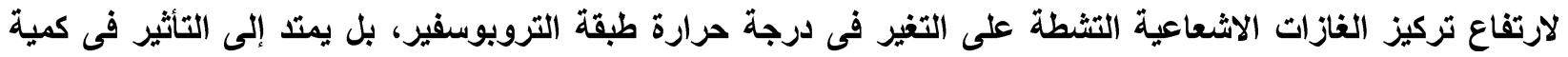


التساقط وفصليتها وتوزيعها الجغرافى ـ ويعد التغير فى كمية التساقط أحد أخطر الاثار الناتجة عن هذه الظاهرة لما لها من

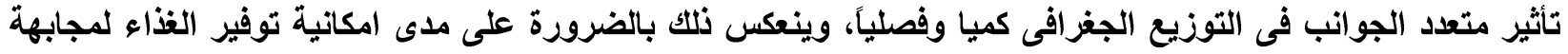

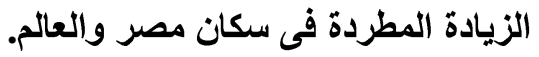

وقد استخدمت ثُلاث هيئات حكومية أحد النماذج العددية للمناخ وهو نموذج AGCM الأى يعبرعن الدورة العامة

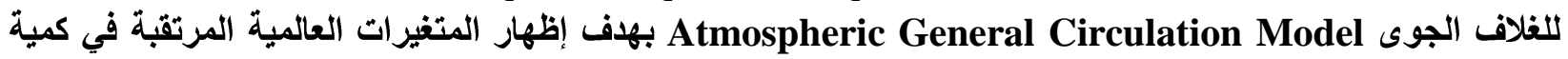

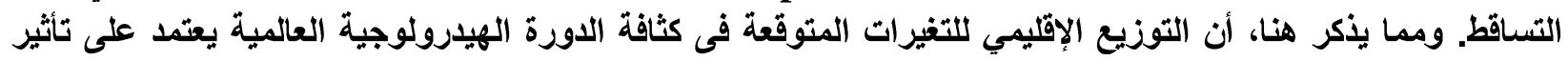

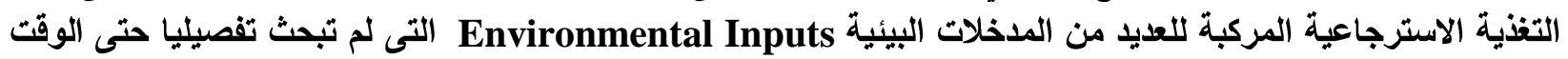

الحاضر. ولذا لم تثقق النماذج المناخ في تحديد توزيعها وكذا امكانية التنبؤ بحدودها القصوى (Roberts, 1994) .

وقد أظهرت النماذج الثلاث UKMO , GFDL , CCC أن :

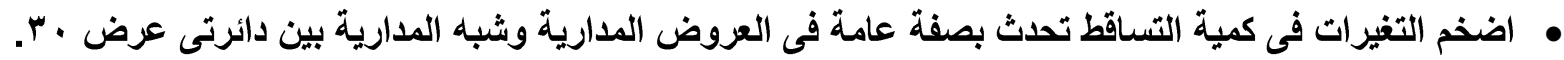

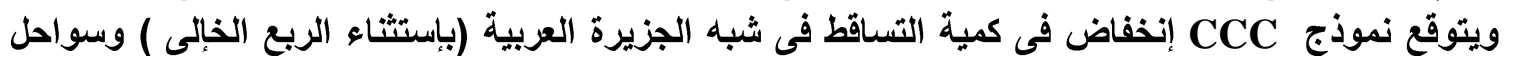

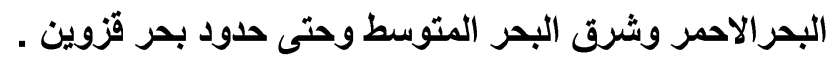

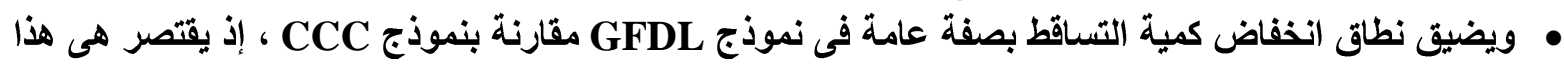

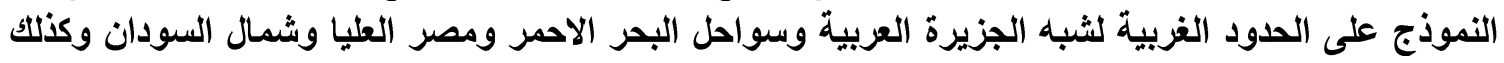
بلاد الشام وشبه القارة الهندية الهود الثربية • ويتوقع نموذج UKMO أن تنفض كمية التساقط فى شبه الجزيرة العربية ووسط آسيا والبحر المتوسط وجنوب اورويا وكذلك بحر العرب والبحر الأحمر.

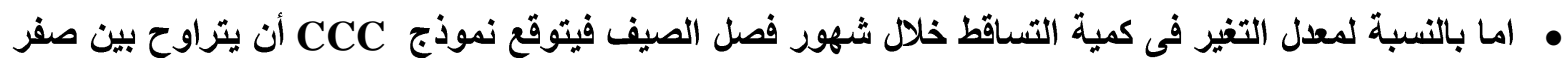

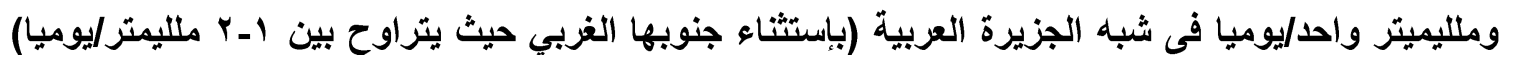

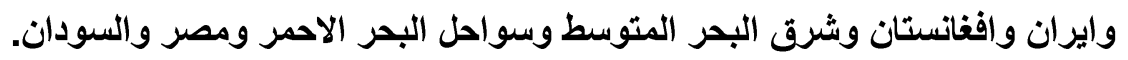

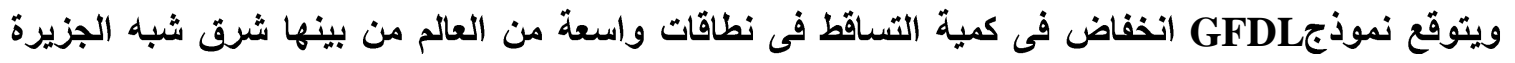

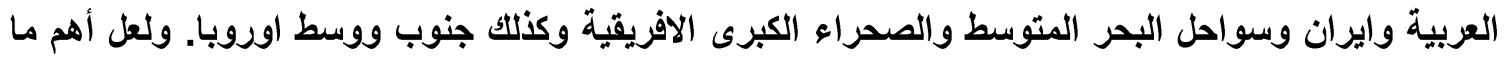

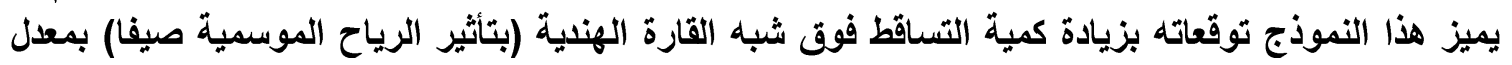

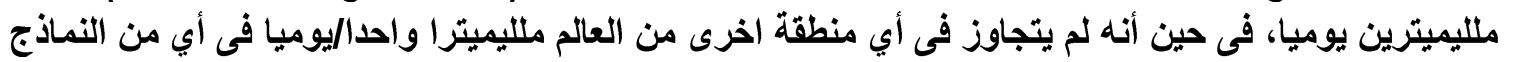

الثلاث.

• ويتسع النطاق المعرض للجفاف فى النموذج UKMO ليشمل معظم المناطق الداخلية من القارات ومن بينها مصر، فضلاً عن المحيطات والبحار المدارية. • تعرض مساحات واسعة من سطح الأرض لمظاهر الجفاف خاصة في قارة أفريقيا التي يصفها الخبيز البيجيري

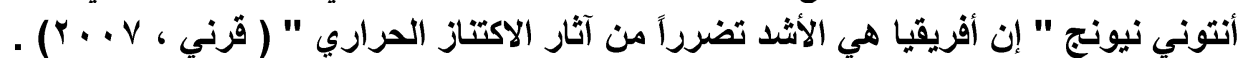

ثالثاً: التغير في المحتوى الرطوبى للتربة : ينعكس تأثير التغيرات العالمية المرتقبة فى كمية التساقط ، حدوث تغير فى رطوية التربة Soil Moisture عند إستخدام نماذج المناخ. ويمكن إيجاز ها في:

يتوقع كل من نموذج GFDL و UKMO أن يزيد جفاف التربة فى معظم أجزاء العالم

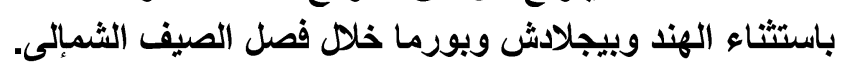

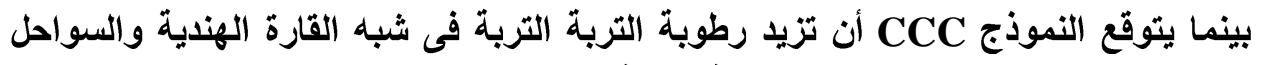

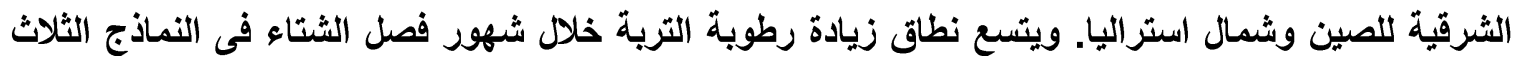
ليشمل شبه القارة الهندية والمناطق الداخلية من قارة اسيا ومناطق متفرقة في امريكا الثمالية وكينيا وتنزانيا. 
ويتوقع نموذج GFDL أن تزيد رطوبة التربة فى نطاق واسع من امريكا الثمالية وشمال

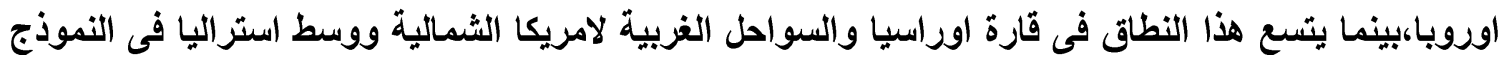
لهذا ولم يتغير الوضع فى شبه الجزيرة العربية شتاء، إذ تتوقع النماذج إستمرار جفاف التربة التهاية كما

رابعاً: ارتفاع درجة حرارة مياه المحيطات:

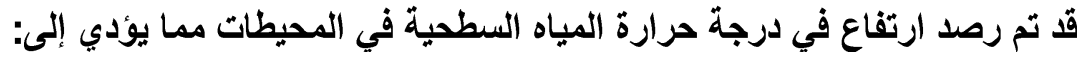
نقص المياه في غرب الولايات المتحدة الأمريكية خلال العثرين سنة التالية التية، وستتعرض إلى الى

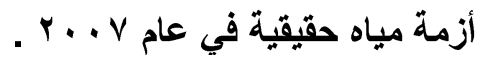

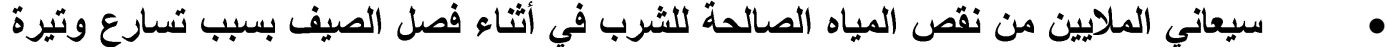

ذوبان الجليد (بارنت: قائد فريق البحث في إدارة أبحاث المناخ في معهد سكريبس لعلواء البوم المحيطات في سان

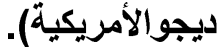

يتمقع العلماء سرعة ذوبان ذالجليد القطبي :

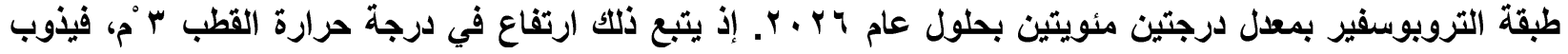
الجليد في الصيف. ويرتبط بهذا عدة آثار سلبية من أهمها:

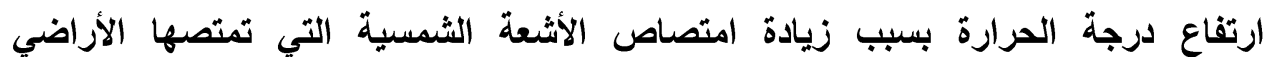

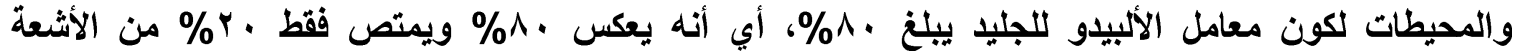

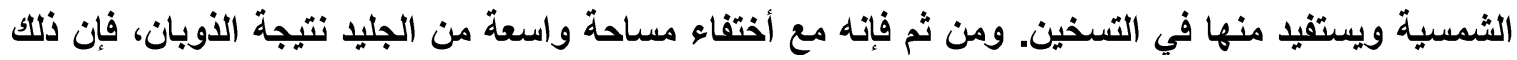

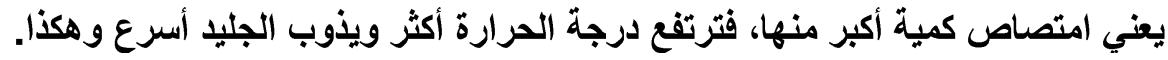

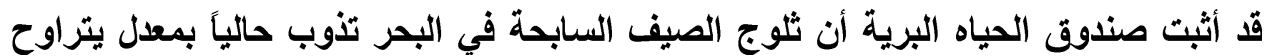

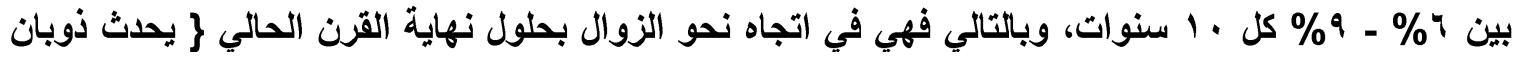
تام $\{$. تثير دراسة قام بها . . r عالماً، أن جليد البحار والسواحل في المنطقة القطبية الثمالية

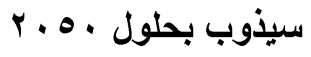
يتبع ذوبان الجليد غمر وغرق · ‘\% من الأراضي المنخفضة والأراضي المزروعة في مناطق

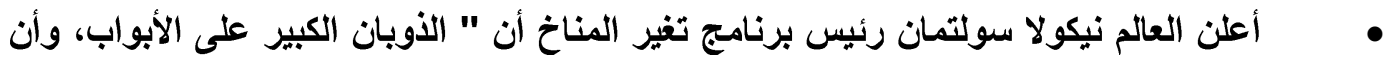

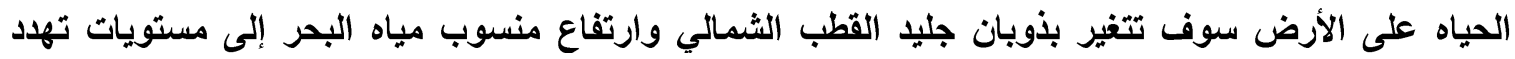

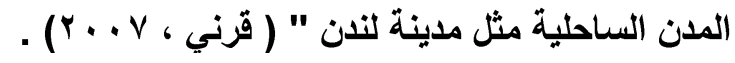
سادساً : ارتفاع مستوى سطح البحر : قد تم رصد الارتفاع في مستوى سطح البطاع البحر على المستوى العالمي، كما ظهر أثره على مستوى سطح البحر

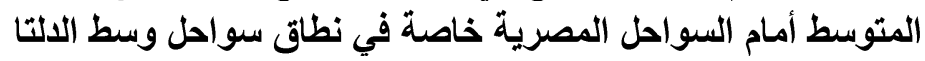
Mohamed El Raey \& Others: COM/ENV/EPOC/DCD/DAC (2004)1/FINAL. 
الآثار المرتقبة لتغير المناخ على الأنثطة البشرية في مصر:

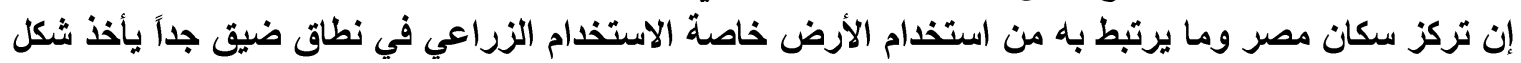

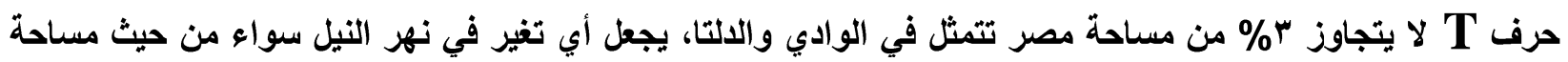

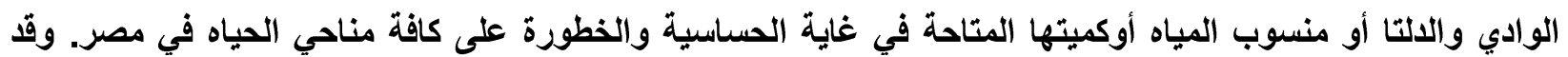

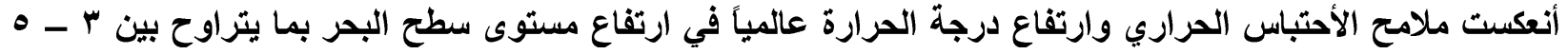

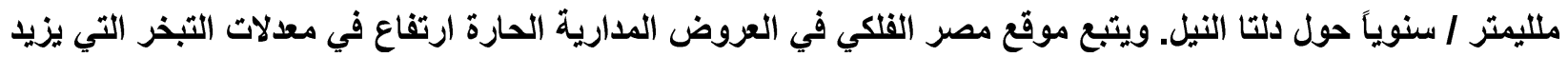

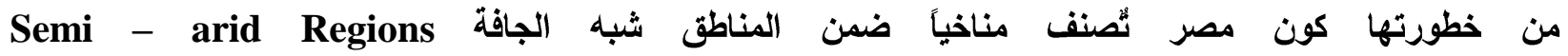

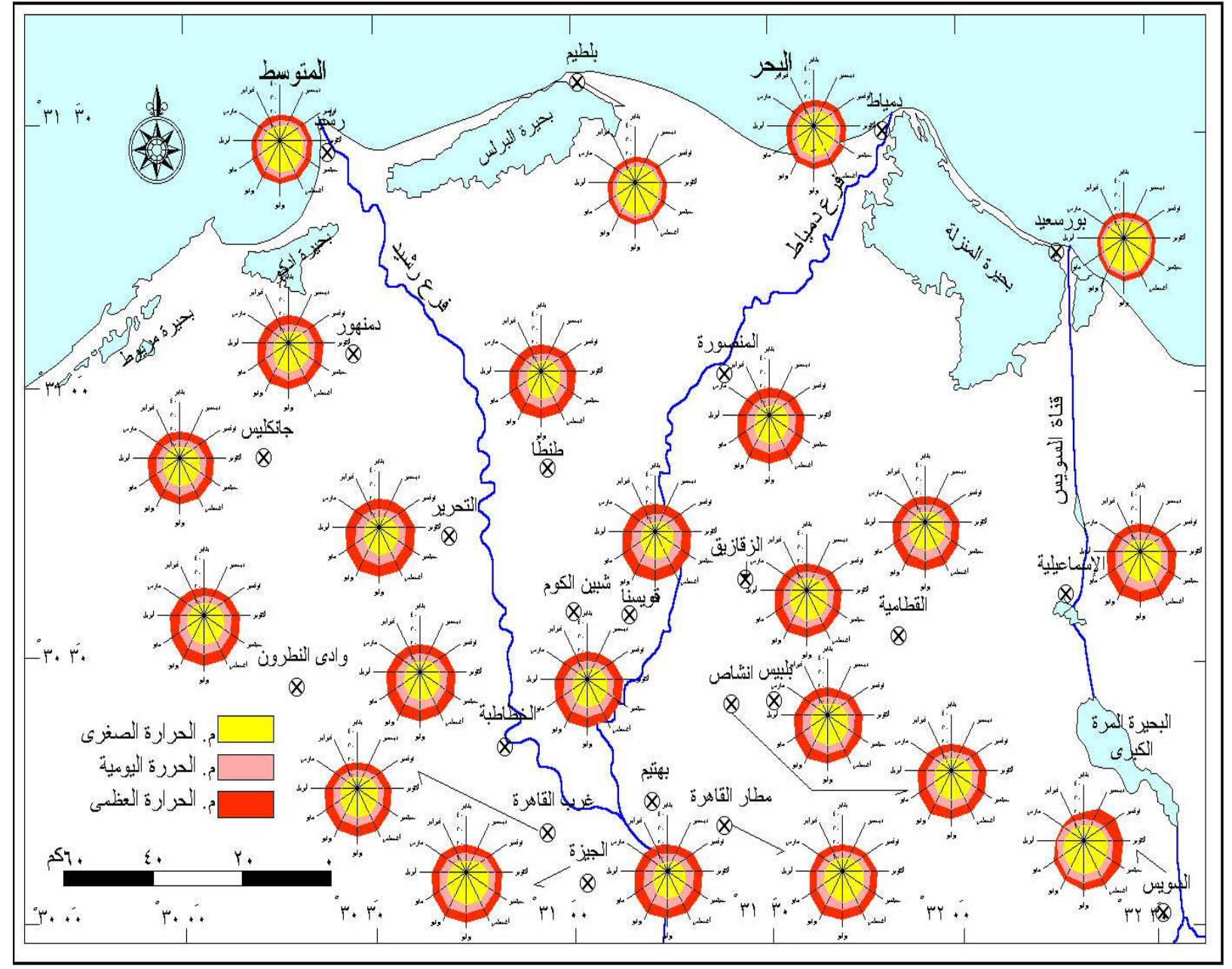

ويتوقع Raey \& Others,2004) كمية الفاقد بالتبخر ستعادل الضعف في ذات التوقت الذي الذي تتضاعف فيه الاحتياجات المائية مع الزيادة السكانية وكثافة مشروعات التمية، وفي المقابل تنذفض فعلياً مياه نهر النيل المتاحة لمصر.

ويمكن تتبع الأبعاد التأثيرية لهذه التغيرات المناخية والبيئية فى مصر في المجالات التالية: 1 ـ التأثثر على الموارد المائبة: 
• يؤدي ارتفاع درجة الحرارة إلى زيادة التبخر من منابع نهز النيل ومجرى النيل في الأراضي

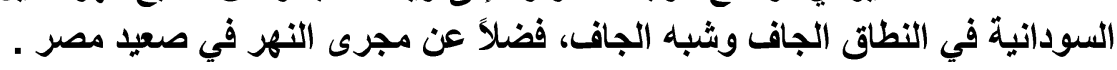

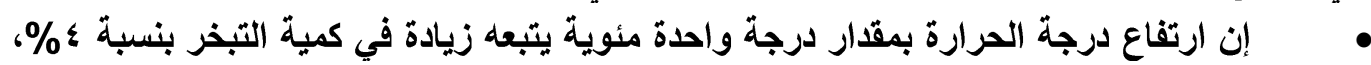

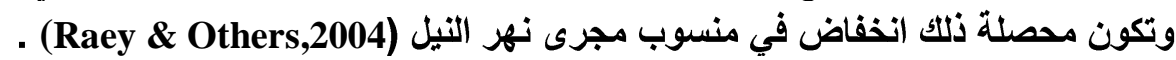

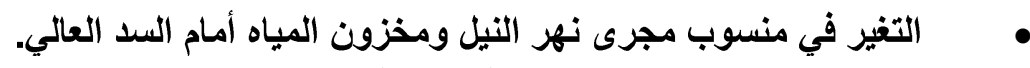
• • يادة الضغط على الموارد المائية المتاحة في جميع مجالات الاستخدام خاصة النشاط الزراعي r ـ التأثير على الاتتاج الزيراعى والحيوانى: الإضي:

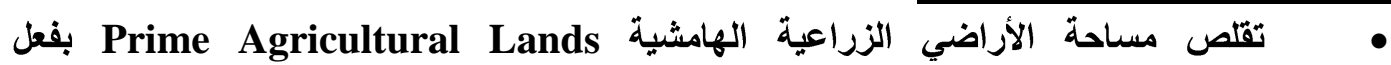
الغرقSalinization Inundation والتمبه بينما تعاني مناطق الزراعة بأسلوب الري الكثيف من نقص مياه

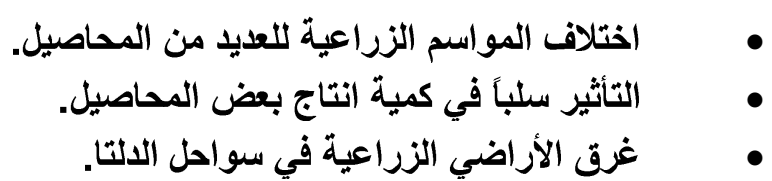

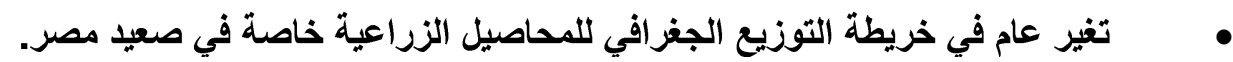

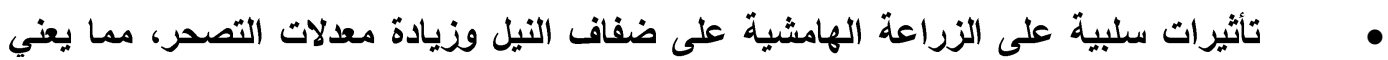
تناقص مساحة الأراضي القابلة للزراعة.

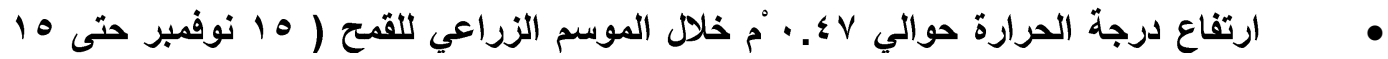

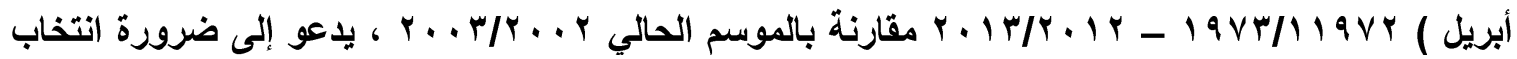

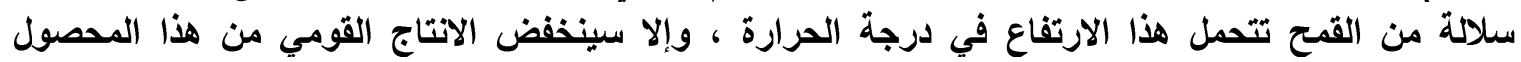
الاستراتيجي . ( Dawod,2004)

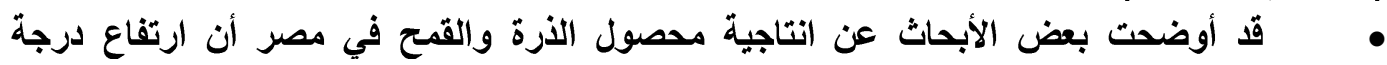

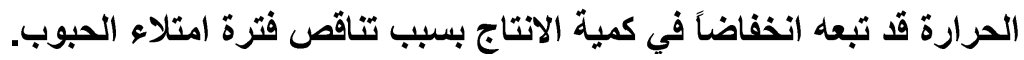

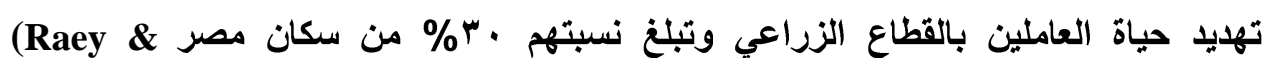
. Others,2004)

r - التأثير على المناطق الساحلية: الإسكندرية.

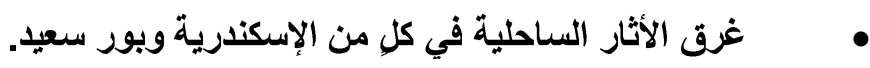

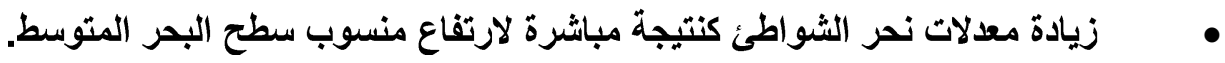

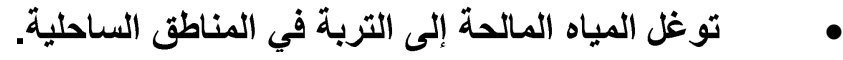

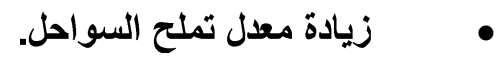

• • ارتفاع منسوب المياه الجوفية في السواحل وبالتالي انخفاض الاتتاجية الزراعية.

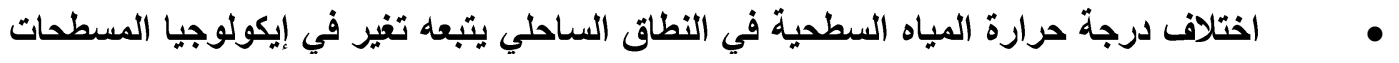
المائية التي تنعكس سلباً على السلسة الغذائية للكائنات البحرية.

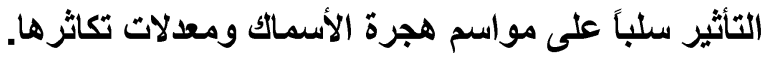


• ارتفاع نسبة الملوحة في بحيرة المنزلة أكبر البحيرات الساحلية في مصر مما يؤثر سلباً في

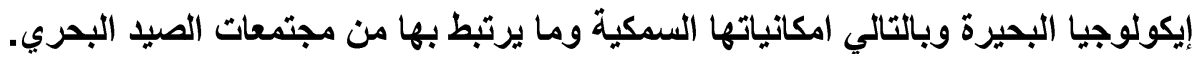

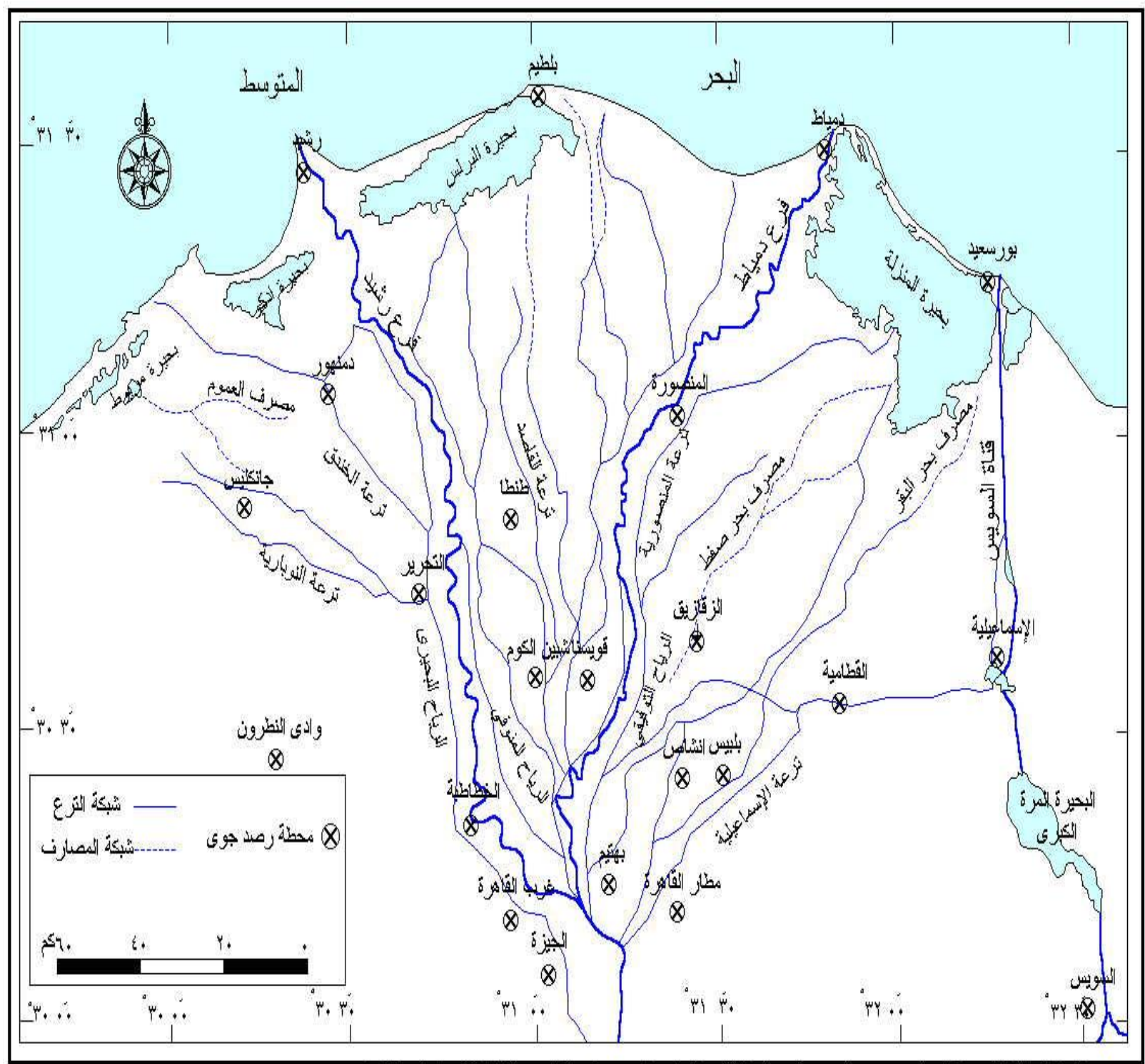

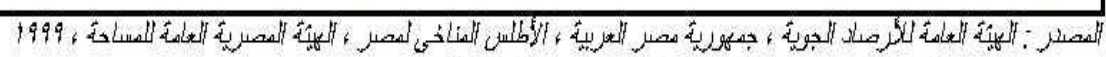

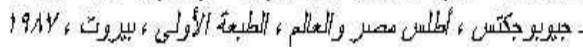

ع - التأثير على المجتمعات العمرانية الساحلية:

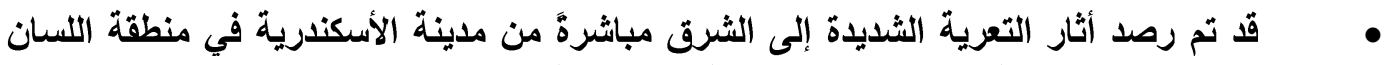

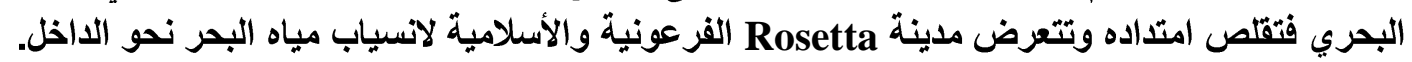

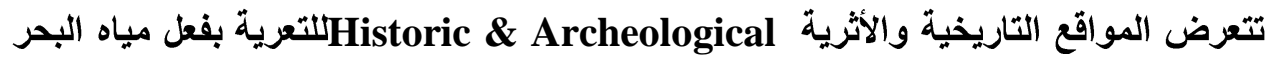


يقدر الفقد في استخدامات الأرض والممتلكات في مدينة الإسكندرية بحوالي ال/ا، بالإضافة إلى

فقدان 9. ب بليون دولار أمريكي (Raey \& Others,2004) .

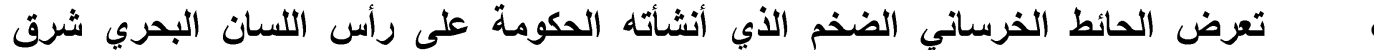

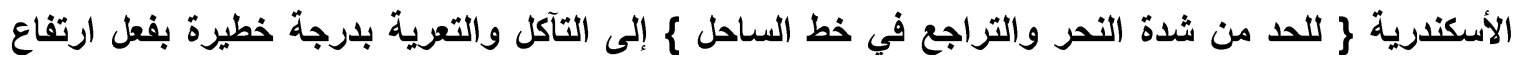

الأمواج .

•

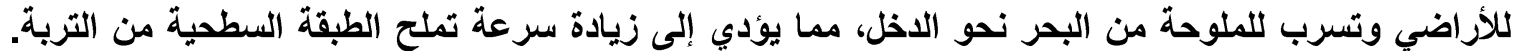

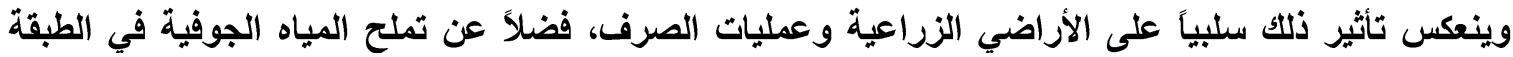

السطحية.

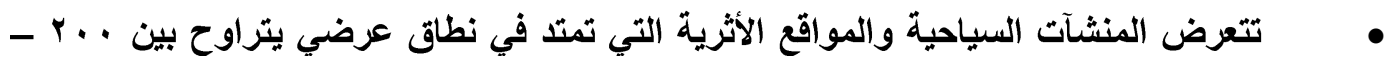

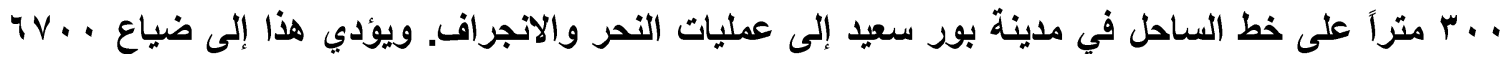

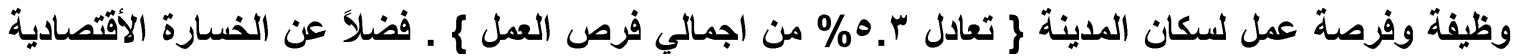

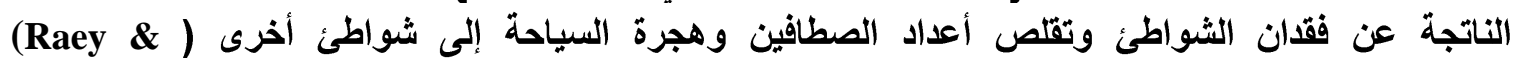
. Others,2004

• ارتفاع مستوى سطح البحر يعني هلم وتراجع كثير من المنشآت الساحلية وزيادة الضغط على الضى

الأراضي وهجرة السكان نحو الداخل.

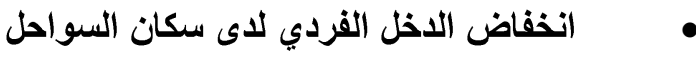

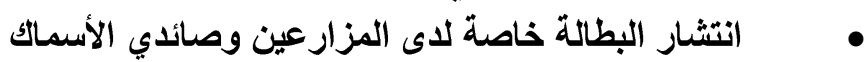

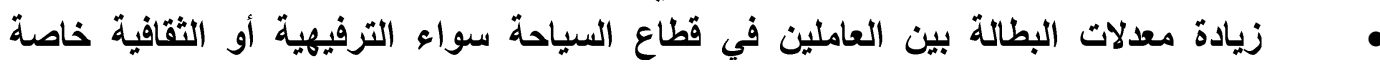

الأثرية.

نقص مساحة الثواطئ الصالحة للمصطافين سنوياً، مما يؤثز سلباً على الخدمات السياحية وارتفاع معدلات البطالة.

تثعرض المناطق العشوائية لأخطار الهام بالسيول.

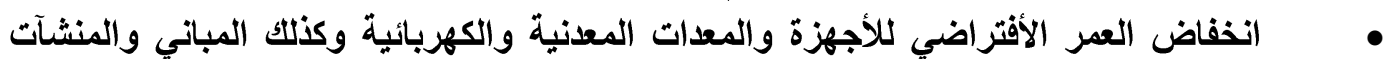

والأمددات والأسلاك الكهربائية واسلاك التليفونات.

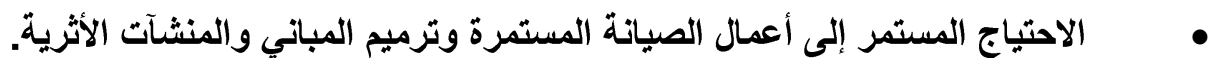

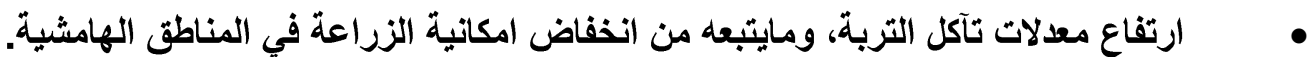

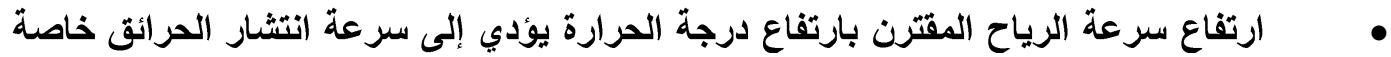

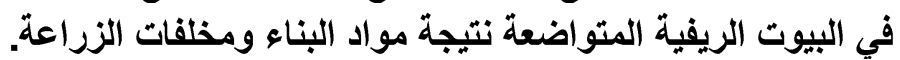

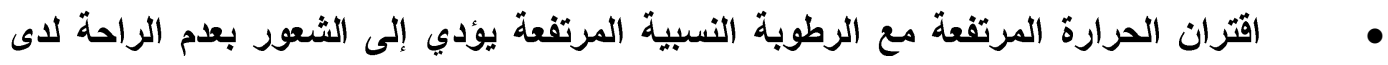

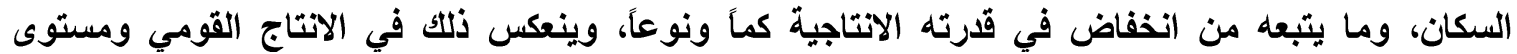

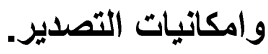

○ـ التأثير على موارد الطاقة:

• سيتضاعف الضغط على احتياجات الطاقة الكهربائية نتيجة لارتفاع درجة الحرارة معظم شهور

السنة.

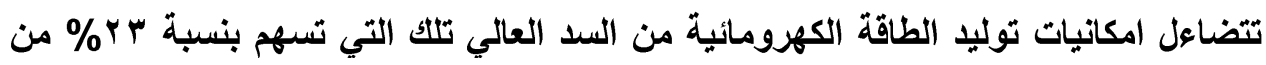

اجمالي الطاقة في مصر كنتيجة لانخفاض منسوب نهر النيل. 
جهود الحكومة المصرية لمجابهة الأثار السلبية لتفير المناخ:

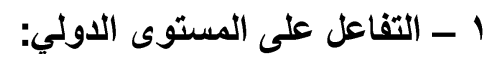

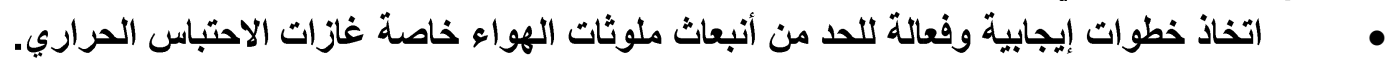

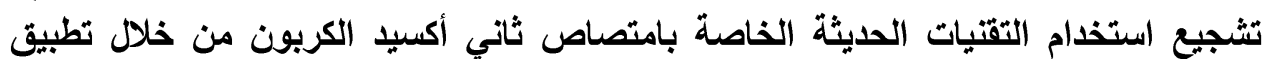
الاتفاقيات الاولية. التنسيق مع دول العالم نحو الالتزام باتفاقية تغير المناخ. التصديق على بروتوكول مونتريال وجميع تعديلاته التي تقتضي الحفاظ على طبقة التهية الأوزون

الأسترتوسفيري. r - التفاعل على المستوى الوطني: وضع البرنامج المصري لحماية طبقة الأوزون، وتثكيل لجنة الأوزون الوطنية، والاهتمام

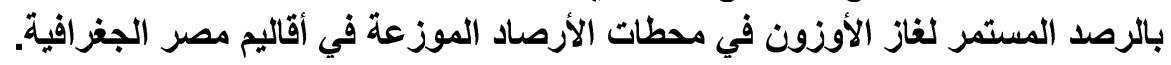

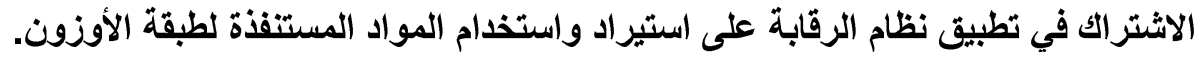

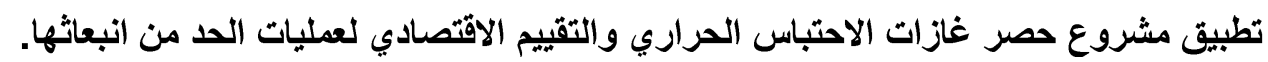

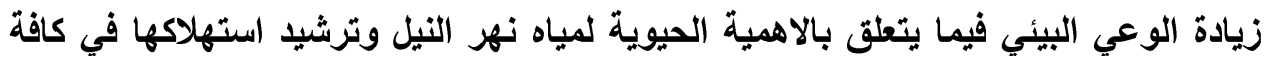
مجالات الحياة. تدعيم مراكز البحث العلمي والجامعات فيما يتعلق ببحث مشكلة تغير المناخ وأثارها على مصر والمنطقة العربية توجيه الاهتمام نحو استخدام موارد الطاقة النظيفة مثل طاقة الرياح للحفاظ على سلامة البيئة

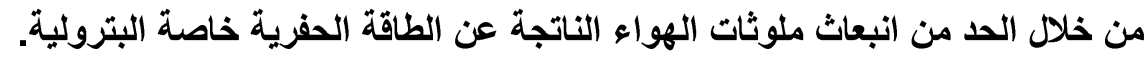

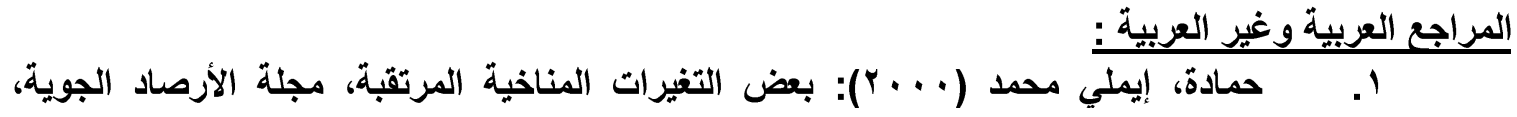
الهيئة العامة للأرصاد الجوية، مصر.

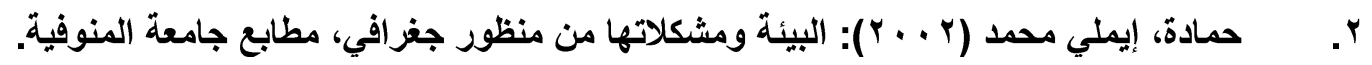

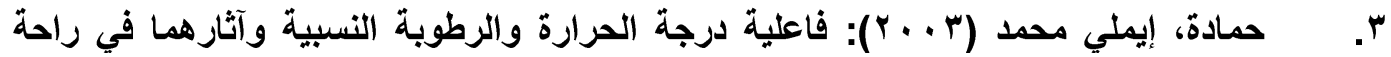

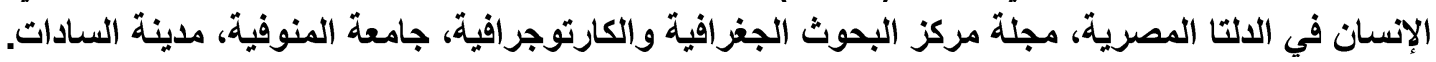

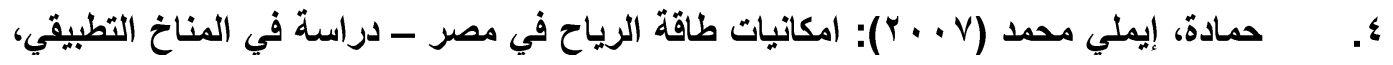

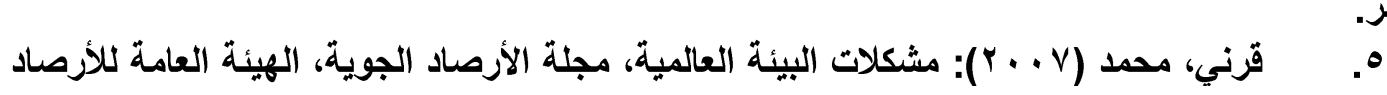
تحث النشر. الجوية.

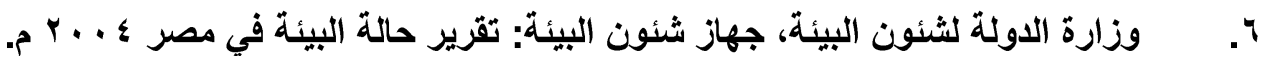

7. Bryant, Margi: The gulf: Pollution and Development, International Institute for Environment and Development, no.24, Earthscan, London, (1980).

8. Cunningham, William \& Barbara Woodwork: Environmental Science, Wm.C. Brown Publishers, U.S.A., (1992). 
9. Dawood, M., (2004): Effect of Climate Change on Wheat Crop over Egypt, Egyptian Meteorological Authority, p22-37.

10. El - Asrag, M., (1999): Climate Change over Egypt and its Relevance to Global Change, Egyptian Meteorological Authority 85-114.

11. Roberts, Neil: the Changing Global Environment, Basil Blackwell, Cambridge, U.S.A., (1994).

12. Shardul Agrawala, Annett Moehner, Mohamed El Raey, Declan Conway, Maarten van Aalst, Marca Hagenstad :Development and Climate Change In Egypt- Focus On Coastal Resources and The Nile COM/ENV/EPOC/DCD/DAC(2004)1/FINA. 